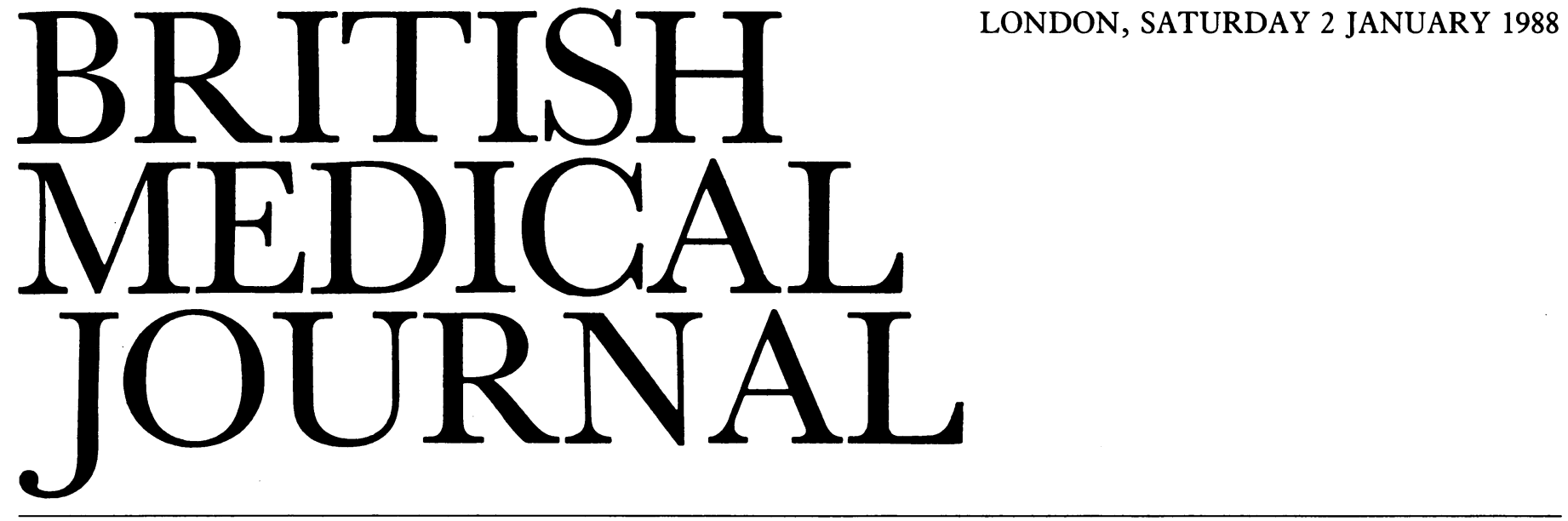

\title{
New Year Message
}

Let us be charitable. Let us assume that Mrs Thatcher and her health ministers really do believe that the NHS is bigger and better funded than ever before and that the concern voiced by the health professions is whingeing in response to tough, effective management. Then how do we convince the government that it is wrong, that the NHS is moving towards terminal decline, and that innovatory thinking is needed to solve the crisis?

To begin with, a mass of misinformation on which the government seems to rely needs correction. As one example on 12 December the Economist claimed that the NHS must be inefficient because there are " 85 nurses for 100000 Britons compared with 50 in America, 45 in France, and 35 in West Germany." Such a claim is careless-the denominator should be 10000 , not 100000 , and completely ignores the wide national differences in the definition of a nurse: in Britain it includes 97000 student nurses-not included in France and Germany-and state enrolled nurses, who carry out tasks that in other countries are done by auxiliaries. In the United States and much of Europe a nurse is a skilled, well paid health professional, usually with a degree. The claim can be rebutted by an equally puzzling statistic: expressed as doctors per 10000 population Britain, with 13.5, comes well behind France $(21 \cdot 8)$ and Germany $(23 \cdot 7){ }^{2}$ As we explained last year, ${ }^{3}$ NHS statistics are bewildering enough for those familiar with them, so it is not surprising that politicians can bounce them backwards and forwards like tennis balls. But there are, we believe, three crucial statements of economic fact that underlie the crisis.

Firstly, Britain spends less on health care than other European countries. As a proportion of the gross national product Britain spends $6 \%$, France $8.5 \%$, Germany $9.5 \%$, The Netherlands $8 \cdot 5 \%$, and Switzerland $7 \cdot 4 \%$. But expressed as dollars per person each year the expenditure by Britain is $\$ 493$, France $\$ 853$, Germany $\$ 1000$, The Netherlands $\$ 828$, and Switzerland $\$ 1111 .^{4}$ That is the extent to which other societies choose to spend more than we do. In the words of the Financial Times "This gap is too large to be explained easily away. Assuming British preferences are similar to those elsewhere the figures suggest that an extra $\$ 10000$ million or so a year could be spent on health care in the
United Kingdom without distorting the overall allocation of economic resources." And those who argue that other countries spend more because they are richer should look at spending on defence, where Britain tops the European league table. ${ }^{6}$

Secondly, the rise in government expenditure on the NHS since 1980 has not kept pace with the targets agreed by its own health ministers. In giving evidence to the House of Commons Social Services Committee these ministers agreed that the level of services needed to rise by $1 \%$ a year to keep pace with the steady increase in old people, by $0.5 \%$ for medical advances, and by $0.5 \%$ for policy objectives such as better community care. ${ }^{7}$ The committee's report, published in 1986 , showed that the rise was well below the recommended $2 \%$. It calculated that "between 1980-1 and 1985-6 the cumulative underfunding of the hospital and community services was $£ 1325$ million at 1985-6 prices after taking full account of the cash releasing cost improvements." ${ }^{\prime 8}$ Furthermore the government has agreed a succession of pay awards for doctors, nurses, and other health workers in excess of its own allowance to the NHS for inflation-so that these health professionals are only too aware that their pay rises (scarcely excessive) have to be funded by health service economies. Yes, the NHS has had a lot more money in the past eight years; no, it has not been enough to maintain agreed standards. Hence the "cuts" in the hospital service-needed to balance health authorities' budgets.

Indeed the crisis is concentrated in the cash limited hospital service. The third grim statistic is that in 1987 NHS managers closed 3500 beds because of lack of money, lack of nurses, or some other similar pressure (and since 1959 the number of NHS hospital beds has declined from 550000 to 400000). ${ }^{9}$ The NHS management board remained silent during this stressful year. Of course, the health authorities always hoped that by closing beds they would save money. In practice very often the doctors and nurses have responded by increasing their working pace, reducing the average bed stay, and so maintaining "throughput." Maybe at first there was some slack in the system; but by now what is happening is that patients are in and out so fast that no one has time to talk 
to them, and the doctors and nurses find themselves exhausted and losing their job satisfaction. The margins are now so narrow that patients are put in danger.

What evidence is there for those last comments? In this issue of the $B M \mathcal{F}$ we begin the publication of two series of articles. In one (p 45) Tony Smith reports interviews with NHS consultants (mostly selected from our leader writers and referees). In the second ( $\mathrm{p} 25$ ) Tony Delamothe reports on the current state of the nursing profession here in Britain and elsewhere.

What these articles will show is that the NHS is under most strain in London and a few other metropolitan districts; teaching hospitals have come under double pressure-from the university cutbacks as well as from NHS underfunding. Hospitals in RAWP gaining districts (which have had money diverted to them from other parts of the NHS) have, for a while, flourished; they have expanded their range of services, opened new buildings, and so on. Of course there are some inefficiencies-but so there are in any mammoth organisation. Variations between districts in indicators such as length of stay mostly reflect these variations in financial stringency-but the shortest stay may not be the best for the patient. And in all districts the future looks bleak; three quarters of the 200 NHS health districts expect to be overspent next year, and that will mean more bed closures. The Government's emergency payment is nothing like large enough to close the gap.

Virtually everywhere the clinicians are disenchanted with the management, which seems unsympathetic and often incompetent. Virtually every hospital is dirty and many are filthy (but then so are Britain's cities-ask any foreign visitor); and many hospitals are unpainted, unrepaired, and unmaintained. Privatisation may have saved money but it has often made standards worse.

In most of Britain nurses are unhappy-with their pay, their working conditions, and their prospects. At any one time half of them are considering leaving nursing; each year about one in ten trained staff do so. In metropolitan areas vacancy rates for trained staff now approach $25 \%$. The resulting increased workload for those who stay leads to stress and poor morale-cited as reasons for leaving as often as the low pay. (The salaries of about two in five of the country's nurses are less than the Low Pay Unit's threshold.) The only way for nurses to improve their prospects is to abandon bedside nursing for teaching or administration, or to emigrate, which increasing numbers are doing.

Finally, everywhere doctors are ashamed of the wages paid to their secretaries. Those who can do so make up their salaries from "soft" research money, or from private earnings, but this solution is not open to all. So many women labour on for less than $£ 6000$ a year (sometimes a lot less) and stay only because of loyalty to their bosses, or to the NHS, or both.

The message that the presidents of the three royal colleges tried to communicate to the prime minister-reinforcing earlier joint criticisms from the BMA, the Royal College of Nursing, and the Institute of Health Services Management ${ }^{9}$ was that after years of squeezing the NHS has finally no more juice to give. If - as the Parliamentary Secretary for Health, Mrs Edwina Currie, has said-NHS expenditure will fall rather than rise as a proportion of gross national product then many health professionals will be reduced to despair.

The only cause for optimism is the growing consensus among doctors, administrators, and politicians that the time has come for a commission of inquiry into the financing and organisation of health care. Britain is not alone in facing a health crisis; in every Western country each year brings new and better treatments for populations that are living longer than ever. This is the insatiable demand that politicians have been citing to excuse their refusal to find more money. But in fact there are many ways of skinning the cat. The choice does not lie simply between Britain's NHS underfunded from taxation and the stark inequalities of the private insurance system in the United States. Many other European countries have systems that provide socialised medicine of a uniformly high standard-so good that there is virtually no private practice as we understand it in Scandinavia. In other parts of Europe the hospitals may be run by independent corporations, the doctors may be paid by fee for item of service, but every citizen can pay for treatment through a compulsory health insurance system, with the state paying for the indigent.

The problem facing all developed countries is that many of the recent advances in medical care predominantly benefit the over $65 \mathrm{~s}$, who may no longer be paying into their health insurance schemes. Any reform of the British NHS will have to take account of this reality. In the United States spending per head on health care for the elderly already averages three and a half times that for the total population; in 1985 the amount was an astounding $\$ 6000$ for every man or woman aged over 65. "Is it," asks Anne Somers, "conceptually possible to design a system that will accommodate the pensioned business executive whose wife has Alzheimer's disease, the poor widow who has worked all her life as a domestic and is now crippled with arthritis and diabetes and has nothing to live on but social security, the dying patient with AIDS, and the 82 year old widower with Parkinson's disease and congestive heart failure?"10

That is the sort of question a new health commission should be asked to examine, and if politicians are to retain the confidence of the public that is where the health debate should be concentrated, not on Mrs Thatcher's tired litany of statistics. The "emergency payment" of $£ 100$ million announced by $\mathrm{Mr}$ Tony Newton on 16 December was little more than a political debating point (p 68). As first priority we believe the government should accept that the NHS is now in a serious short term financial crisis and that solving that crisis is more important to the country than cutting two pence off the standard rate of income tax (cost, $£ 2500 \mathrm{~m}$ ). Health authorities should be given revised, realistic budgets for the coming year; and the government should undertake to fund in their entirety the pay awards to be made to doctors and nurses in April. These two measures could give a breathing space of a year for a health commission to come up with proposals that will retain a comprehensive health service while finding sources of funding that will bring spending on health in Britain into line with that in the rest of northern Europe.

ToNy SMITH

Deputy editor, $B M \mathcal{F}$

1 Anonymous. Honing health. Economist 1987 Dec 12:18-9.

2 Abel-Smith B, ed. Eurocare. Vol 1. Basle: Health Service Consultants, 1986:189.

3 Smith T. Deux chevaux, Jaguar-or Ford. Br Med f 1987;294:1636.

4 Abel-Smith B, ed. Eurocare. Vol 1. Basle: Health Service Consultants, 1986:68.

5 Anonymous. Health care dilemmas. Financial Times $1987 \mathrm{Dec}$ 9:22 (cols 1-2).

6 Radical Statistics Nuclear Disarmament Group. The Nuclear Numbers Game. London, Radical Statistics, 1982.

7 Anonymous. A rise is a rise is a rise [Editorial]. $\mathrm{Br} \mathrm{Med} \mathcal{f}$ 1987;293:290.

8 Social Services Committee. Fourth Report. Public expenditure on the social services. London: HMSO, 1986. (Short Report.)

9 Anonymous. BMA, IHSM, and RCN want NHS spending to rise with national income. BrMed $\mathcal{F}$ 1987;294:1695.

10 Somers AR. Insurance for long-term care. N Engl F Med 1987;317:23-9. 